\title{
Cerebrospinal fluid transthyretin: aging and late onset Alzheimer's disease
}

\author{
J-M Serot, D Christmann, T Dubost, M Couturier
}

\begin{abstract}
The deposition of insoluble $\beta$-amyloid protein fibrils is probably the central event in the pathogenesis of Alzheimer's disease. Cerebrospinal fluid inhibits this fibril formation, likely by the intervention of one or several proteins binding to soluble $\beta$-amyloid protein. In vitro, transthyretin (TTR), a CSF protein, impedes amyloid fibrillogenesis. Lowered concentrations of CSFTTR could therefore be associated with Alzheimer's disease. Concentrations of TTR in CSF samples from 149 consecutive patients were assayed, using a kinetic nephelemetric method. These concentrations were correlated positively with age, but were significantly lower in patients with Alzheimer's disease. These data raise the possibility that amyloid fibril formation could be promoted in patients with late onset Alzheimer's disease by the lack of sufficient concentrations of TTR.
\end{abstract}

(F Neurol Neurosurg Psychiatry 1997;63:506-508)

Keywords: transthyretin; cerebrospinal fluid; Alzheimer's disease; aging

Transthyretin (TTR) is a protein of 508 amino acids with a molecular weight of $55 \mathrm{kDa}$. This tetrameric protein, which occurs in plasma and CSF, is composed of four identical $\beta$ pleated subunits with a central channel. ${ }^{1}$ The gene encoding TTR is located on chromosome 18; TTR is synthesised by the liver and, in the brain, only by the epithelial cells of the choroid plexus. In rats, serum TTR concentrations are 10 times higher than TTR concentrations inCSF, ${ }^{1}$ but the TTR/CSF protein ratio (up to $25 \%$ of intraventricular proteins) is much higher than the $\mathrm{TTR} /$ serum protein ratio $(0.5 \%)$. In vitro, TTR constitutes $20 \%$ of newly synthesised proteins and $50 \%$ of the proteins secreted by the choroid plexus. ${ }^{1}$ The TTR present in CSF is catabolised by the liver, muscles, and skin, probably after reabsorption by arachnoid villi. ${ }^{1}$ The CSF-blood barrier prevents the passive diffusion of serum TTR into CSF; therefore TTR in CSF comes almost uniquely from the choroid plexus. ${ }^{1}$ Concentra- tions of TTR are nearly the same in ventricular and lumbar CSF. ${ }^{1}$ The synthesis of serum TTR and TTR in CSF are regulated independently. Fasting reduces serum concentrations whereas CSF concentrations remain unchanged. ${ }^{1}$ Several TTR mutations have been documented, many of which are associated with systemic or cerebral amyloid deposition; however, none of these mutations are linked to Alzheimer's disease. ${ }^{12}$

TTR is a transport protein for thyroxin and plasma retinol binding protein. It could have other functions, especially as it sequesters the $\beta$-amyloid protein in vitro. ${ }^{3} \mathrm{~A}$ decrease of TTR concentration in CSF among severely demented patients with Alzheimer's disease has been reported. ${ }^{4}$ To evaluate whether concentrations of TTR in CSF are decreased in Alzheimer's disease we measured the concentrations in CSF in 149 consecutive patients.

\section{Patients and methods}

CSF was obtained from 149 patients: 17 young patients under 20 years old (five males, 12 females, mean age 10.4 (SD 5.4) years), 51 middle aged patients between 20 and 60 years old (21 men, 30 women, mean age 41 (SE 11) years), and among the remaining patients over 60 years old, 41 elderly controls (13 men, 28 women, mean age 76.2 (SD 7.7) years) and 40 patients (13 men, 27 women, mean age 74.2 (SD 5.8) years) with dementia and fulfilling the diagnosis of probable Alzheimer's disease according to the NINCDS-ADRDA criteria. ${ }^{5}$ All patients had undergone a lumbar puncture to rule out a neurological disease such as a CNS infection, a subarachnoid haemorrhage, or a degenerative disc disease.

All CSF samples had a protein concentration $<0.60 \mathrm{~g} / \mathrm{l}$ and less than three cells $/ \mathrm{ml}$. The TTR concentrations were measured in residual CSF samples after CSF had been examined routinely. Albumin and TTR were assayed by a kinetic nephelemetric method using an automated nephelometer (Beckman Specific Protein Analyzer, Array 360 System; Brea, CA, USA) with antialbumin and anti-TTR antibodies (Beckman Instruments, Galway, Ireland). Samples of CSF were centrifuged before analysis to remove contaminants. Specimens not tested immediately were frozen and stored at $-30^{\circ}$. For each assessment series a survey of 
Albumin and TTR concentrations in lumbar CSF of patients with Alzheimer's disease (AD) v controls

\begin{tabular}{lllll}
\hline & $\begin{array}{l}\text { Young } \\
\text { controls }\end{array}$ & $\begin{array}{l}\text { Middle aged } \\
\text { controls }\end{array}$ & $\begin{array}{l}\text { Elderly } \\
\text { controls }\end{array}$ & $\begin{array}{l}\text { Patients } \\
\text { with } A D\end{array}$ \\
\hline No & 17 & 51 & 41 & 40 \\
Mean (SD) age (y) & $10.4(5.4)$ & $41.0(11.0)$ & $76.0(7.7)$ & $74.2(5.8)$ \\
Age range & $2-18$ & $20-53$ & $61-90$ & $61-88$ \\
Male/female ratio & $5 / 12$ & $21 / 30$ & $13 / 28$ & $13 / 27$ \\
Mean (SD) TTR (mg/l) & $15.54(1.82)^{\star \star \star}$ & $17.37(2.35)$ & $20.02(2.45)^{\star \star \star}$ & $17.49(2.02)$ \\
Mean (SD) albumin $(\mathrm{mg} / 1)^{\star}$ & $113(44)^{\star \star \star}$ & $211(70)$ & $217(76)$ & $216(61)$ \\
\hline
\end{tabular}

$\star \star \star \mathrm{P}<0.001 v$ patients with $\mathrm{AD}$.

standardisation with pre-established dilutions (Vigil PRX, Beckman Instruments, Brea, CA, USA) was performed.

Statistical analysis using Student's $t$ tests was performed with the Slide Write Plus software (Carlsbad, CA, USA). Significance was considered for $\mathrm{P}$ values $<0.05$.

\section{Results}

In the younger control group the mean concentration of TTR in CSF was 15.54 (SD 1.82) $\mathrm{mg} / \mathrm{l}$, significantly different $(\mathrm{P}<0.0001)$ from the mean concentration in the elderly control group (20.02 (SD 2.45) $\mathrm{mg} / \mathrm{l}$ ) and in the middle aged control group (17.37 (SD 2.35) $\mathrm{mg} / \mathrm{l} ; \mathrm{P}<0.001)$. The concentration of TTR in CSF in patients with Alzheimer's disease (17.49 (SD 2.02) mg/l) was not significantly different from that of middle aged patients $(P=0.8)$, but significantly lower than that of aged control patients $(\mathrm{P}<0.0001)$. The table summarises these results.

Concentrations of TTR in CSF increased progressively with aging, at a rate of $0.06 \mathrm{mg} / 1$ every year (figure).

The mean concentration of albumin in CSF was lower in young patients (113 (SD 44) mg/l) than in middle aged patients (211 (SE 70) $\mathrm{mg} / \mathrm{l})$. It was not different in patients with Alzheimer's disease (216 (SD 61) mg/l) and in the elderly control group (217 (SD 76) $\mathrm{mg} / \mathrm{l}$ ).

\section{Discussion}

This study reports an increase in concentration of TTR in CSF with age, except in patients with Alzheimer's disease, who display signifi-

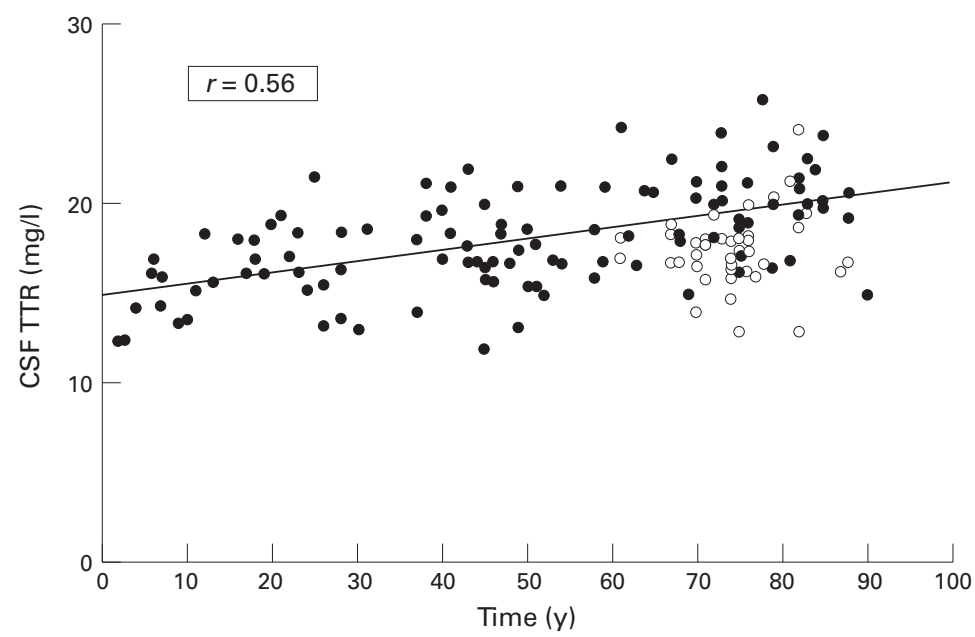

Concentrations of TTR in CSF of control subjects ( $\bullet$ ) and patients with Alzheimer's disease (O) measured with a kinetic nephelemetric method. Concentrations of TTR are correlated positively with age in patients free from Alzheimer's disease. cantly lower concentrations despite some overlap between patients with Alzheimer's disease and aging controls .

The increase in concentration of TTR in $\mathrm{CSF}$ with age could be evaluated at $0.06 \mathrm{mg} / \mathrm{l}$ per year in our study, a feature previously reported by others but unexplained. ${ }^{6}$ Concentrations of TTR in CSF result from simultaneous phenomena: secretion and filtration by the choroid plexus, passive diffusion through the blood-CSF barrier, and reabsorption. Albumin has a molecular weight of $65 \mathrm{kDa}$, in the same range as TTR. According to some authors (for review see Kalaria $^{7}$ ), albumin concentrations rise in the CSF of aging patients, although serum albumin concentrations decrease, suggesting an increased blood-CSF barrier leakage particularly in the case of leukoaraiosis. ${ }^{8}$ Other authors have reported that CSF albumin concentrations do not increase with age, ${ }^{7}$ and our study similarly shows no change. This seems to indicate that the increase of TTR concentrations in CSF with age is not due to a disorder of the blood-CSF barrier permeability. Indeed May et al reported a decrease in CSF filtration rates from $0.41 \mathrm{ml} / \mathrm{min}$ at 28 years of age to $0.19 \mathrm{ml} / \mathrm{min}$ at 77 years of age, ${ }^{9}$ probably related to modifications of the choroid plexus, such as thickened stroma, appearance of psammomas and cysts, and increased thickness of the epithelial basement membrane. ${ }^{10}{ }^{11}$ All these features could support a reduction of CSF filtration in elderly people.

In patients with Alzheimer's disease, concentrations of TTR in CSF were lower than in aging control subjects whereas albumin concentrations in CSF were in the same range, indicating a decrease of TTR secretion. This hypothesis is consistent with several other features. For instance, in rats, chronic lead exposure impairs the function of $\mathrm{CP}$, and concentrations of TTR in CSF are decreased. ${ }^{12}$ The epithelium of the choroid plexus transports vitamin B12 from blood into CSF, and vitamin B12 concentrations have been reported to be lowered in the CSF of patients with Alzheimer's disease. ${ }^{13}$ Isotopic scinticysternography detects hydraulic anomalies in CSF in patients with Alzheimer's disease such as reversal flow with ventricular reflux or delayed clearance. ${ }^{14}$ Histological studies performed on the choroid plexus in Alzheimer's disease have reported an important stromal fibrosis, ${ }^{15}$ and the height of choroid plexus epithelial cells is significantly higher in elderly controls than in patients with Alzheimer's disease. ${ }^{11}$

The deposition of $\beta$-amyloid fibrils is probably a central event in the pathogenesis of Alzheimer's disease, and sequestration of $\beta$-amyloid protein has been reported to prevent amyloid formation. ${ }^{3}$ In vitro, CSF inhibits $\beta$-amyloid fibril formation, and it has been suggested that this phenomenon could be related to its interaction with one or several sequestering proteins such as $\alpha$-1-antichymotrypsin, apolipoproteins $\mathrm{E}$ (apoE) and $\mathrm{J}$ (apoJ), or TTR. ${ }^{16}$ Indeed, $\alpha$-1-antichymotrypsin is able to prevent $\beta$-amyloid fibrillogenesis in vitro, and could induce fibril 
disaggregation. ${ }^{17}{ }^{18}$ An interaction between ApoE and $\beta$-amyloid is suggested by the fact that ApoE immunoreactivity is found in senile plaques, and because this lipoprotein prevents $\beta$-amyloid aggregation in vitro. ${ }^{3}$ The $\beta$-amyloid/ApoE interaction is influenced by the $\beta$ sheet conformation of the amyloid peptides used and by the purification of ApoE. ${ }^{19}{ }^{20}$ The more important avidity of the native ApoE3 allele products is attenuated by purification, whereas ApoE3 and ApoE4 exhibit similar avidity when they are purified. These data could explain the apparent discrepancy of previously reported data. ${ }^{19}$ It has also been reported that the presence of equimolar complexes of apoJ and $\beta$-amyloid protein in CSF indicates that apoJ acts as a carrier protein. ${ }^{21}$ Finally, in human CSF under physiological conditions, TTR forms soluble complexes by binding to $\beta$-amyloid protein. An important inhibition of amyloid aggregation is found at a molar ratio of 1:300, which suggests that TTR concentrations in CSF could be the major $\beta$-amyloid binding protein. ${ }^{322}$ As CSF concentration of $\beta$-amyloid have been reported to increase with age, ${ }^{23}$ the concomitant increase in TTR concentrations that we report here could be an important feature maintaining $\beta$-amyloid in soluble complexes. In Alzheimer's disease, this physiological sequestration could be imperfect, owing to inadequate concentrations of TTR, the last being possibly related to epithelial atrophy in the choroid plexus in patients with late onset Alzheimer's disease.

1 Ingenbleek Y, Young V. Transthyretin (prealbumin) in health and disease: nutritional implications. Annu Rev Nutr 1994;14:495-533.

2 Palha JA, Moreira P, Wisniewski T, Frangione B, Saraiva MJ. Transthyretin gene in Alzheimer's disease patients. Neurosci Lett 1996;204:212-4.

3 Schwarzman AL, Gregori L, Vitek MP, Luybski S, Strittmatter WJ, Engehilde JJ, Bhasin R, Silverman J, Weisgraber KH, Coyle PK, Goldgaber D. Transthyretin sequesters amyloid $\beta$ protein and prevents amyloid formation. ters amyloid $\beta$ protein and prevents
Proc Natl Acad Sci 1994;91:8368-72.

4 Riisøen H. Reduced prealbumin (transthyretin) in CSF of Riisøen H. Reduced prealbumin (transthyretin) in CSF of severely demented patients with
Neurol Scand 1988;78:455-9.

5 McKahn G, Drachman D, Folstein M, Katzmann R, Price D, Stadlan EM. Clinical diagnosis of Alzheimerís disease: report of the NINCDS-ADRDA Work Group under the auspices of Department of Health and Human Services Task Force on Alzheimer's disease. Neurology 1984;34: 939-44.
6 Kleine TO, Hackler R, Dauch W, Zöfel P. Transport and production of cerebrospinal fluid (CSF) change in aging humans under normal and diseased conditions. $Z$ Gerontol 1993;26:251-5.

7 Kalaria RN. The blood-brain barrier and cerebral microcirculation in Alzheimer disease. Cerebrovasc Brain Metab Rev 1992;4:226-60.

8 Pantoni L, Inzitari D, Pracucci G, Lolli F, Giordano GP, Bracco L, Amaducci L. Cerebrospinal fluid proteins in patients with leucoaraiosis: possible abnormalities in blood-brain barrier function. $\mathcal{F}$ Neurol Sci 1993;115:12531.

9 May C, Kaye JA, Atack JR, Schapiro MB, Friedland RP, Rapoport SI. Cerebrospinal fluid is reduced in healthy aging. Neurology 1990;40:500-3.

10 Shuanghoti S, Netsky MG. Human choroid plexus: morphologic and histochemical alterations with age. $A m \mathcal{F}$ Anat 1970;128:73-96.

11 Serot JM, Béné MC, Foliguet B, Faure GC. Altered choroid plexus basement membrane and epithelium in late-onset Alzheimer disease: an ultrastructural study. Ann N-Y Acad Sci 1997 (in press).

12 Zheng W, Shen H, Blaner WS, Zhao Q, Ren X, Graziano $\mathrm{H}$. Chronic lead exposure alters transthyretin concentration in rat cerebrospinal fluid: the role of the choroid plexus. Toxicol Appl Pharmacol 1996;139:445-50

13 IkedaT, Furukawa Y, Mashimoto S, Takahashi K, Yamada M. Vitamin B12 levels in serum and cerebrospinal fluid of people with Alzheimer's disease. Acta Psychiatr Scand 1990;82:327-9.

14 Brusa G, Claudiani F, Piccardo A, Pizio N, Stoeh R. Scinticysternography in presenile and senile degenerative disease. Ital F Neurol Sci 1990;11:43-7.

15 Jellinger K. Neuropathological aspects of dementias resulting from abnormal blood and cerebrospinal fluid dynamics. Acta Neurol Belg 1976;76:83-102.

16 Wisniewski T, Castano E, Ghiso J, Frangione B. Cerebrospinal fluid inhibits $\beta$ amyloid fibril formation in vitro. Ann Neurol 1993;34:631-3.

17 Aksenova MV, Aksenov NY, Butterfield DA, Carney JM. Alpha-1-antichymotrypsin interaction with A beta (1-40) inhibits fibril formation but does not affect the peptide toxicity. Neurosci Lett 1996;211:45-8.

18 Fraser PE, Nguhen GT, McLachlan DR, Abraham CR, Kirschner D. $\alpha$ 1-Antichymotrypsin binding to Alzheimer's A $\beta$ peptides is sequence specific and induces fibril disaggregation. F Neurochem 1993;61:298-306.

19 Ladu MJ, Pederson TM, Frail DE, Reardon CA, Getz GS, Falduto MT. Purification of apolipoprotein E attenuates isoform-specific binding to $\beta$ amyloid. If Biol Chem 1995;270:9039-42.

20 Golabek AA, Soto C, Vogel T, Wisniewski T. The interaction between apolipoprotein $\mathrm{E}$ and Alzheimer's amyloid $\beta$ peptide is dependent on $\beta$ peptide conformation. 7 Biol Chem 1996;271:10602-6.

21 Matsubara E, Frangione B, Ghiso J. Characterization of apolipoprotein J-Alzheimer's A $\beta$ interaction. $f$ Biol Chem 1995;270:7563-7.

22 Schwarzman AL, Goldgaber D. Interaction of transthyretin with amyloid $\beta$-protein: binding and inhibition of amyloid formation. In: Bock GR, Goode JA, eds. The nature and origin of amyloid fibrils. Chichester: Wiley (Ciba Foundation Symposium 199), 1996:146-64.

23 van Gool WA, Schenk DB, Bolhuis PA. Concentrations of amyloid- $\beta$ protein in cerebrospinal fluid increase with age in patients free from neurodegenerative disease. Neurosci Lett 1994;172:122-4. 